\title{
문 17-12-12
}

\section{전력케이블에서 반도전 재료의 이온성 불순물에 따른 열적 특성}

\section{Thermal Properties According to lonic Impurities of Semiconductive Material in Power Cable}

\author{
이경용 ${ }^{1, a}$, 최용성', 박대희 ${ }^{1}$ \\ (Kyoung-Yong Lee ${ }^{1, a}$, Yong-Sung Choi ${ }^{1}$, and Dae-Hee Park')
}

\begin{abstract}
In this paper, we have investigated thermal properties and impurities content of specimens showing by changing the content of carbon black that is semiconductive materials for underground power transmission. Specimens were made of sheet form with the three of existing resins and the nine of specimens for measurement. Impurities content of specimens was measured by ICPAES(Inductively Coupled Plasma Atomic Emission Spectrometer). Heat capacity $(\Delta \mathrm{H})$ and melting temperature $(\mathrm{Tm})$ were measured by DSC(Differential Scanning Calorimetry). The ranges of measurement temperature were from $0{ }^{\circ} \mathrm{C}$ to $200{ }^{\circ} \mathrm{C}$, and heating temperature was $4{ }^{\circ} \mathrm{C} / \mathrm{min}$. And then thermal diffusivity was measured by LFA 447. The measurement temperature was $25^{\circ} \mathrm{C}$. Impurities content was highly measured according to increasing the content of carbon black from ICPAES results. And heat capacity and melting temperature from the DSC results were simultaneously decreased according to increasing the content of carbon black, while thermal diffusivity was increased according to increasing the content of carbon black. Because ionic impurities of carbon black containg $\mathrm{Fe}, \mathrm{Co}, \mathrm{Mn}, \mathrm{Al}$, and $\mathrm{Zn}$ were rapidly increasing kinetic energy by vibration of ionic impurities through the applied heat energy.
\end{abstract}

Key Words : Semiconductive shield, lonic impurities, Heat capacity, Melting temperature, Thermal diffusivity

\section{1. 서 론}

반도전층은 도체로부터의 전계완화와 도체와 절 연체간 직접 접촉됨으로써 발생하는 문제점들을 완화시키기 위해 사용된다. 그러나 본래 목적과는 달리 반도전층은 많은 이온성불순물들을 함유하고 있어서 절연총의 절연열화를 가속시킨다. 즉, 반도 전층 내에서 절연층으로 확산된 불순물에 열이나 전기적인 스트레스가 집중하여 부분방전이 일어나

1. 원광대학교 전기전자 및 정보공학부

(전북 익산시 신용동 344-2)

a. Corresponding Author: leeky@wonkwang.ac.kr

접수일자 : 2004. 8. 4

1차 심사 : 2004. 11. 4

2차 싱사 : 2004. 11. 11

심사완료 : 2004. 11. 15
고 이는 절연층의 열화로 이어져 결국 열 열화 및 전기트리로 성장하여 절연파괴를 일으킨다[1].

이러한 케이블의 절연파괴를 예방하기 위한 많 은 노력이 진행되어, 결과적으로 전력케이불의 불 순물은 현저히 감소되고 있는 추세이다. 그러나 국 내에서 발생한 배전용 전력케이블 고장을 분석한 결과에 의하면, 케이블 내에는 상당히 많은 양의 이온성 불순물이 존재한다는 사실이 밝혀졌다. 이 들 불순물은 정밀 분석기기로 측정될 수 있는 이 온성의 불순물로 특히, 외부반도전층에 다량 함유 되어 있었다. 이러한 불순물들은 고분자의 산화반 웅에 참여하여 열화를 가속시키며 열화과정을 통 해 고분자 내에 극성을 부여함으로써 소수성기의 화학구조를 친수성으로 변화시켜 수분의 유입을 가져오게 한다. 또한 반도전층 주변의 열에 의한 
열화도 초래하게 된다[2-5].

따라서, 본 논문에서는 전력케이블의 수명연장 및 신뢰성을 확보하기 위해 현제 국내케이블에 사 용되고 있는 반도전 재료와 측정용 시편을 이용하 여 절연열화 요인 중 한가지인 열적특성을 측정하 였다.

우선, ICPAES 장비를 사용하여 각 반도전 재료 의 이온성 불순물을 측정하였으며, 이러한 불순물 에 따른 열적 특성을 열분석 장치인 $\mathrm{DSC}$ 를 사용 하여 반도전 재료의 열용량 $(\Delta \mathrm{H})$ 과 이온성 불순물 들이 반도전 재료에 미치는 용융온도 $(\mathrm{Tm})$ 등을 측정하였다. 마지막으로 Nano Flash Diffusivity를 사용하여 불순물들이 반도전재료의 열확산도에 미 치는 영향을 측정하였다. 이와 같이 우리는 반도전 층내에 존재하는 이온성 불순물들로 인한 열적 특 성들을 고찰함으로써 전력케이블 반도전층의 성능 향상이 시급함을 강조하고자 하였다.

\section{2. 시편 및 실험방법}

\section{1 시편 제작}

본 논문에서는 EVA(Ethylene Vinyl Acetate, 현대석유화학), EEA(Ethylene Ethyl Acrylate, ATO FINA), EBA(Ethylene Buthyl Acrylate, Mitsui D upont)를 기본재료로 사용하였는데 이들 재료의 조성비는 표 1 과 같다. 표 1에서 보는 바와 같이 본 논문에서는 도전성 카본볼랙의 함량을 변 수로 하였으며 그 함량은 각각 $20,30,40 \mathrm{wt} \%$ 이 었다.

그리고 편의상 측정용 시편을 \#숫자, 국내에서 제조되어 사용되고 있는 수지를 A숫자로 명명하였 다. 시트는 pellet 형태의 원료를 $70 \sim 100{ }^{\circ} \mathrm{C}$ 의 롤러에서 5 분간 혼련한 후, $180{ }^{\circ} \mathrm{C}$ 에서 20 분간 200 $\mathrm{kg} / \mathrm{cm}^{2}$ 의 압력으로 프레싱을 하여 시트상으로 제 작하였다.

\section{2 실험장비 및 방법}

반도전 재료의 이온성 불순물 함량을 측정하 기 위해 사용된 장비는 무기원소를 $\mathrm{ppm}$ 수준으로 분석할 수 있는 ICPAES (Perkin Elmer Instruments, Optima $3300 \mathrm{DV}$ )이다. 본 실험에 사용된 시편들은 고체 고분자이므로 전처리 과정을 거친 후 실험을 진행하였다.
표 1. 시편들의 조성.

Table 1. Composition of specimens.

Unit : wt \%

\begin{tabular}{|c|c|c|c|c|c|c|c|}
\hline $\begin{array}{c}\text { Spec- } \\
\text { imen }\end{array}$ & EVA & EEA & EBA & $\begin{array}{c}\text { Carbon } \\
\text { Black }\end{array}$ & Additive & Agent & Total \\
\hline \hline$\# 1$ & 78.2 & - & - & 20 & 1.3 & 0.5 & 100 \\
\hline$\# 2$ & 68.6 & - & - & 30 & 0.6 & 0.5 & 100 \\
\hline$\# 3$ & 58.9 & - & - & 40 & 0.6 & 0.5 & 100 \\
\hline$\# 4$ & - & 78.2 & - & 20 & 1.3 & 0.5 & 100 \\
\hline$\# 5$ & - & 68.6 & - & 30 & 0.6 & 0.5 & 100 \\
\hline$\# 6$ & - & 58.9 & - & 40 & 0.6 & 0.5 & 100 \\
\hline$\# 7$ & - & - & 78.2 & 20 & 1.3 & 0.5 & 100 \\
\hline$\# 8$ & - & - & 68.6 & 30 & 0.6 & 0.5 & 100 \\
\hline$\# 9$ & - & - & 58.9 & 40 & 0.6 & 0.5 & 100 \\
\hline A1 & 53.8 & - & - & 38.7 & 6.9 & 0.6 & 100 \\
\hline A2 & - & - & 53.8 & 38.7 & 6.9 & 0.6 & 100 \\
\hline A3 & - & - & 57.8 & 37.2 & 4.5 & 0.6 & 100 \\
\hline
\end{tabular}

반도전 재료내의 이온성 불순물이 각 시편의 열용량 $(\Delta \mathrm{H})$ 와 용융온도 $(\mathrm{Tm})$ 에 미치는 영향을 측정하기 위해 사용된 열 분석 장비는 $\mathrm{DSC}$ (TA Instrument, DSC 2920)이다. DSC의 촉정온도 범 위는 $0{ }^{\circ} \mathrm{C}$ 에서 $200{ }^{\circ} \mathrm{C}$ 까지이고, 승온속도는 $4{ }^{\circ} \mathrm{C} /$ $\mathrm{min}$ 이었다. 보통 $\mathrm{DSC}$ 는 선형온도 프로그램을 이 용하게 되는데 시편과 기준물질 (또는 불활성 pan) 을 일정한 속도로 승온/냉각하거나 어떤 온도에 유 지시키는 등온 실험이 가능하지만, 본 실험에서는 승온에 의해 실험이 이루어졌다.

마지막으로 시편들의 열 확산도를 측정하기 위 해 사용 된 Nano Flash Diffusivity (NETZSCH, $\mathrm{LFA}$ 447)의 측정온도는 $25{ }^{\circ} \mathrm{C}$ 이다. 이 장비는 ASTM E1461 규격에 적합한 장비로서 제논플래시 (Xenon Flash) 램프를 광원으로 채용한다. 제논 플 래시 램프는 시편 아래쪽에 위치하여 구동되고 시 편의 위쪽으로 전달되는 열은 상단부에 위치한 적 외선 센서 (IR detector)에 의해 측정된다. 측정된 데이터는 소프트웨어에 의해 계산되어 시편의 열 확산도 (Thermal Diffusivity)가 측정된다. 


\section{3. 실험 결과}

\subsection{ICPAES 분석}

표 2는 국내에서 사용되고 있는 카본블랙내 이 온성 불순물의 함량을 나타낸 것이다. 그리고 표 3 은 각 반도전 재료/카본블랙. 복합재료에서 카본블 랙 함량을 변량시켰을 때, 검출된 이온성 불순물의 함량을 나타낸 것이다. 아직까지 지중 송전용 케이 블에 대한 명확한 이온성 불순물 함량의 제한치가 제시되지 않았기 때문에 $22.9 \mathrm{kV} \mathrm{CV} / \mathrm{CV}-\mathrm{W}$ 한전 규격[4]을 토대로 실험을 진행하였다.

한전사양에는 총 10 가지의 이온성 불순물을 제 시하고 있다. 즉, $\mathrm{Ca}, \mathrm{Si}, \mathrm{Fe}, \mathrm{Al}, \mathrm{Zn}, \mathrm{Cu}, \mathrm{Mg}, \mathrm{Na}$, $\mathrm{Ni}, \mathrm{K}$ 등이다. 나열된 불순물들을 보면 카본(C)은 제외되어 있다. 카본을 제외한 나머지 원소들을 불 순물로 취급하는 이유는 두가지 측면으로 설명될 수 있다.

첫째, 카본은 안정적인 구조로 외력에 대해 잘 반응을 하지 않지만, 나열된 불순물들은 양이온으 로 존재함으로써 외력에 대해 반응을 일으켜 트리 현상을 발생시킨다. 여기서 외력이란 불순물 주변 의 열, 전계 및 수분 등을 말한다.

또 하나는 카본은 탄소의 사슬로 된 집합체로서 고분자와 유사한 구조를 가지지만 불순물들은 구 조가 달라서 전력케이블내 전류의 흐름에 방해가 되어 집중적인 공격을 받아 절연파괴의 원인이 된 다. 실제로, 위 두가지 사항 때문에 고전압에서는 이온성 불순물에 대한 규제를 강화하고 있다.

표 2. 카본블랙내 이온성 불순물.

Table 2. Ionic impurities in carbon black.

Unit : ppm

\begin{tabular}{|c|c|}
\hline 종류 & Content \\
\hline \hline $\mathrm{Ca}$ & - \\
\hline $\mathrm{Si}$ & 5475.64 \\
\hline $\mathrm{Cu}$ & 49.78 \\
\hline $\mathrm{Fe}$ & 14.38 \\
\hline $\mathrm{Al}$ & 334.07 \\
\hline $\mathrm{Zn}$ & 13.27 \\
\hline $\mathrm{Mg}$ & - \\
\hline $\mathrm{Ni}$ & 3.32 \\
\hline $\mathrm{Na}$ & 817.47 \\
\hline $\mathrm{K}$ & 313.05 \\
\hline $\mathrm{Total}$ & $\mathbf{7 0 2 0 . 9 8}$ \\
\hline
\end{tabular}

한전사양에 의하면 내부 반도전의 이온성 불순 물 함량치가 $500 \mathrm{ppm}$ 이하, 외부 반도전의 이온성 불순물 함량치가 $1500 \mathrm{ppm}$ 이하로 제시되어 있다. 표 2에서 카본블랙내의 불순물 총 함량이 7020.98 ppm인 것을 확인할 수 있었다. 상당량의 불순물이 카본블랙내에 함유되어 있었으며 아직까지 저급의 카본블랙이 국내에서 유통되고 있는 것을 알 수 있었다.

특히, $\mathrm{Si}, \mathrm{Al}, \mathrm{Na}, \mathrm{K}$ 등의 불순물들이 상당량 검 출되었다. 표 2 의 결과에 따라 알아 본 복합재료의 이온성 불순물들을 표 3 에 제시하였다.

표 3에서 알 수 있듯이 카본블랙의 함량이 종 가함에 따라 이온성 불순물 함량은 641.815 $4316.861 \mathrm{ppm}$ 의 범위에서 중가하고 있는 것을 확 인할 수 있었다.

\section{표 3. 복합재료의 이온성 불순물.}

Table 3. Ionic impurities of composites.

Unit : ppm

\begin{tabular}{|c|c|c|c|c|c|c|}
\hline 종류 & $\# 1$ & $\# 2$ & $\# 3$ & $\# 4$ & $\# 5$ & $\# 6$ \\
\hline $\mathrm{Ca}$ & $\begin{array}{l}131 . \\
308\end{array}$ & $\begin{array}{l}134 . \\
482\end{array}$ & $\begin{array}{l}163 . \\
728\end{array}$ & $\begin{array}{l}133 . \\
181\end{array}$ & $\begin{array}{l}124 \\
768\end{array}$ & $\begin{array}{l}101 . \\
941\end{array}$ \\
\hline $\mathrm{Si}$ & $\begin{array}{l}330 \\
720\end{array}$ & $\begin{array}{l}309 . \\
359\end{array}$ & $\begin{array}{c}1410 \\
105\end{array}$ & $\begin{array}{l}154 . \\
545\end{array}$ & $\begin{array}{c}221 . \\
811\end{array}$ & $\begin{array}{l}609 . \\
002\end{array}$ \\
\hline $\mathrm{Cu}$ & - & - & - & - & - & - \\
\hline $\mathrm{Fe}$ & 35.766 & 63.546 & 41.519 & 22.272 & 39.279 & 50.750 \\
\hline $\mathrm{Al}$ & - & 2.955 & 5.875 & - & 23.105 & - \\
\hline $\mathrm{Zn}$ & 0.489 & 0.492 & 2.350 & - & - & - \\
\hline $\mathrm{Mg}$ & 27.927 & 29.064 & 26.233 & 22.727 & 27.726 & 22.065 \\
\hline $\mathrm{Ni}$ & 3.919 & 6.896 & 4.700 & 4.545 & 4.621 & 4.413 \\
\hline $\mathrm{Na}$ & $\begin{array}{l}208 . \\
231\end{array}$ & $\begin{array}{c}213 . \\
300\end{array}$ & $\begin{array}{l}689 . \\
385 \\
\end{array}$ & $\begin{array}{l}231 . \\
818 \\
\end{array}$ & $\begin{array}{l}263 \\
401 \\
\end{array}$ & $\begin{array}{l}150 . \\
044\end{array}$ \\
\hline K & 80.352 & 76.847 & 7.442 & 72.727 & 78.558 & 66.195 \\
\hline Total & $\begin{array}{c}818 . \\
712\end{array}$ & $\begin{array}{l}836 . \\
941\end{array}$ & $\begin{array}{c}2351 . \\
347\end{array}$ & $\begin{array}{l}641 . \\
815\end{array}$ & $\begin{array}{l}783 . \\
269\end{array}$ & $\begin{array}{c}1004 \\
410\end{array}$ \\
\hline
\end{tabular}




\begin{tabular}{|c|c|c|c|c|c|c|}
\hline 종류 & $\# 7$ & $\# 8$ & $\# 9$ & $\mathrm{~A} 1$ & $\mathrm{~A} 2$ & A3 \\
\hline $\mathrm{Ca}$ & $\begin{array}{l}110 . \\
209\end{array}$ & $\begin{array}{l}126 . \\
023\end{array}$ & $\begin{array}{l}126 . \\
453\end{array}$ & $\begin{array}{l}160 . \\
095\end{array}$ & $\begin{array}{l}181 . \\
367\end{array}$ & $\begin{array}{l}147 . \\
962\end{array}$ \\
\hline $\mathrm{Si}$ & $\begin{array}{l}461 . \\
331\end{array}$ & $\begin{array}{l}905 . \\
368\end{array}$ & $\begin{array}{l}959 . \\
302\end{array}$ & $\begin{array}{l}356 . \\
294\end{array}$ & $\begin{array}{l}213 . \\
082\end{array}$ & $\begin{array}{c}1920 \\
714\end{array}$ \\
\hline $\mathrm{Cu}$ & - & - & - & - & - & - \\
\hline $\mathrm{Fe}$ & 17.941 & 26.387 & 12.112 & 19.002 & 23.786 & 20.658 \\
\hline $\mathrm{Al}$ & - & 4.549 & - & - & - & 22.33 \\
\hline $\mathrm{Zn}$ & 4.271 & 4.549 & - & $\begin{array}{l}593 . \\
824\end{array}$ & $\begin{array}{l}569 . \\
871\end{array}$ & 5.583 \\
\hline Mg & 25.630 & 31.847 & 29.069 & $\begin{array}{c}2926 \\
365\end{array}$ & $\begin{array}{c}2958 . \\
374\end{array}$ & 27.917 \\
\hline $\mathrm{Ni}$ & - & - & 4.844 & 4.750 & - & - \\
\hline $\mathrm{Na}$ & $\begin{array}{l}175 . \\
138\end{array}$ & $\begin{array}{l}195 . \\
632\end{array}$ & $\begin{array}{l}203 . \\
488\end{array}$ & $\begin{array}{l}194 . \\
774\end{array}$ & $\begin{array}{l}213 . \\
082\end{array}$ & $\begin{array}{l}240 . \\
089\end{array}$ \\
\hline $\mathrm{K}$ & 68.346 & 68.243 & 67.829 & 61.757 & 69.375 & 94.919 \\
\hline Total & $\begin{array}{c}862 . \\
876\end{array}$ & $\begin{array}{c}1362 . \\
598\end{array}$ & $\begin{array}{c}1403 \\
097\end{array}$ & $\begin{array}{c}4316 \\
861\end{array}$ & $\begin{array}{c}4228 . \\
937\end{array}$ & $\begin{array}{c}2480 \\
175\end{array}$ \\
\hline
\end{tabular}

- : Not detected or less than 0.05 ppm

그리고 대부분의 측정용 시편들은 내부 반도전 의 제한치인 $500 \mathrm{ppm}$ 이상을 나타내고 있었다. 그 러나 측정용 시편 중 \#3을 제외한 나머지는 외부 반도전의 제한치 아래에 있었다. 이 결과로부터 $\mathrm{EEA}$ 의 불순물 함량치가 다른 시편들에 비해 적게 검출되어 대체적으로 우수한 특성을 보었다[5].

이 결과에서 주목할 만한 사실은, 현재 국내에 서 제조되어 사용되고 있는 세 개의 시편 모두 외 부 반도전의 제한치인 $1500 \mathrm{ppm}$ 이상을 나타내고 있다는 것이다. 특히 $\mathrm{A} 1$ 과 $\mathrm{A} 2$ 의 불순물 함량치는 $4000 \mathrm{ppm}$ 이상으로서, 현재 국내 반도전 케이블의 상태가 매우 불안정하다는 것을 알 수 있었다.

\section{2 열적 특성}

그림 1-4는 $0{ }^{\circ} \mathrm{C}$ 에서 $150{ }^{\circ} \mathrm{C}$ 까지의 온도 범위에 서 카본블랙의 함량에 따른 열용량과 용융온도를 나타낸 것이다. 그림 1-4와 표 3에서 알 수 있듯 이, 이온성 불순물들을 다량 함유하고 있는 카본블 랙의 함량이 증가함에 따라 열용량은 $31.84 \mathrm{~J} / \mathrm{g}$ $58.12 \mathrm{~J} / \mathrm{g}$, 용융온도는 $63{ }^{\circ} \mathrm{C} \sim 70.53{ }^{\circ} \mathrm{C}$ 의 범위에 서 감소하는 것을 알 수 있다.

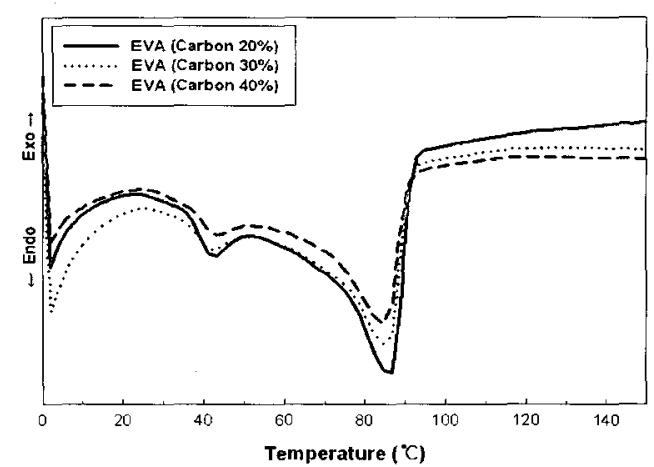

그림 1. 카본블랙의 함량에 따른 $\mathrm{EVA}$ 의 열적 특성.

Fig. 1. Thermal properties of EVA by content of carbon black.

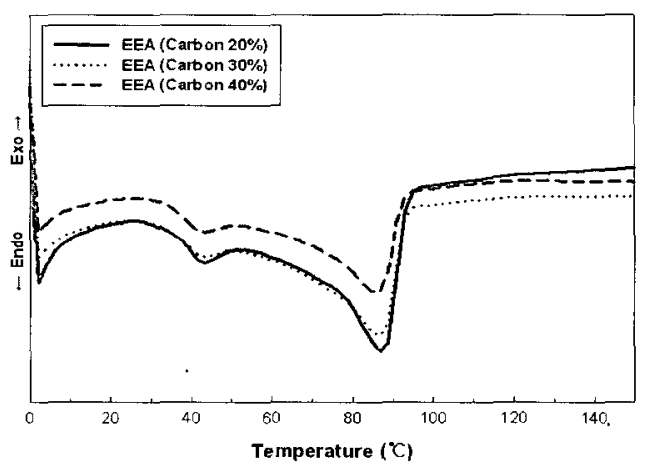

그림 2. 카본볼랙의 함량에 따른 $\mathrm{EEA}$ 의 열적 특성.

Fig. 2. Thermal properties of EEA by content of carbon black.

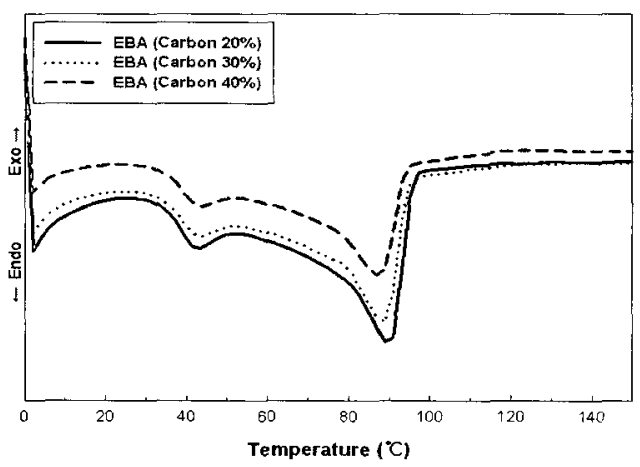

그림 3. 카본블랙의 함량에 따른 $\mathrm{EBA}$ 의 열적 특성.

Fig. 3. Thermal properties of EBA by content of carbon black. 
이것은 카본블랙이 함유하고 있는 $\mathrm{Fe}, \mathrm{Co}, \mathrm{Mn}$, $\mathrm{Al}, \mathrm{Zn}$ 등의 이온성 불순물들이 인가된 열에너지 에 의해 입자들의 진동이 증가하면서 근접한 입자 들과 단위시간 동안 부딪히는 횟수가 증가하여 자 유 운동에너지가 더 빨리 전달되기 때문인 것으로 사료된다. 여기서 용융온도가 감소하면 재료의 가 공성이 우수한 장점도 있지만 열예 취약한 특성을 보여 재료의 수명에 악영향을 미쳐 열화에 이르게 된다[6-8]. A1, A2 및 A3 수지의 경우 열용량은

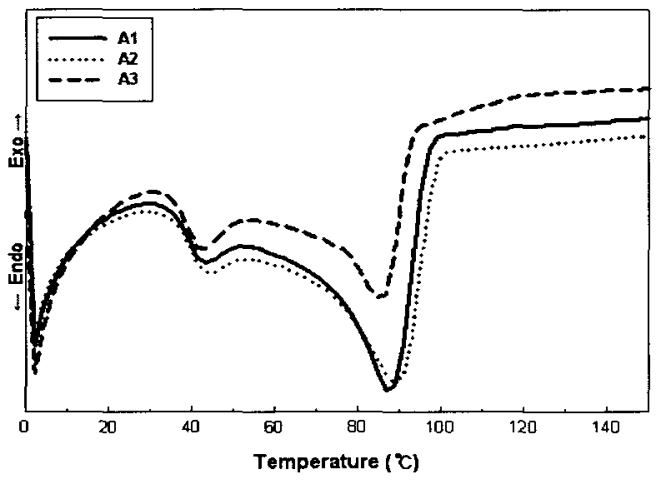

그림 4. 카본블랙의 함량에 따른 기존수지의 열적 특성.

Fig. 4. Thermal properties of existing resins by content of carbon black.

표 4. 카본블랙의 함량에 따른 반도전 재료의 열적 특성.

Table 4. Thermal properties of semiconductive materials by content of carbon black.

\begin{tabular}{|c|c|c|}
\hline 종류 & $\Delta \mathrm{H}[\mathrm{J} / \mathrm{g}]$ & $\operatorname{Tm}\left[{ }^{\circ} \mathrm{C}\right]$ \\
\hline$\# 1$ & 56.57 & 65.21 \\
\hline$\# 2$ & 45.10 & 64.13 \\
\hline$\# 3$ & 39.27 & 63 \\
\hline$\# 4$ & 58.12 & 70.53 \\
\hline$\# 5$ & 49.22 & 69.35 \\
\hline$\# 6$ & 39.08 & 67.22 \\
\hline$\# 7$ & 54.41 & 66.81 \\
\hline$\# 8$ & 44.80 & 64.53 \\
\hline$\# 9$ & 37.20 & 64.30 \\
\hline A1 & 45.72 & 73.61 \\
\hline A2 & 45.97 & 64.07 \\
\hline A3 & 31.84 & 65.83 \\
\hline
\end{tabular}

다른 시편에 비해 다소 낮게 나타났지만 용융온도 는 대체적으로 고온에서 발생하였음을 알 수 있다.

이와 같은 결과들을 동해 대체적으로 $\mathrm{EEA}$ 의 열적 안정성이 다른 시편들에 비해 우수함을 알 수 있었다.

그림 5 는 카본블랙의 함량에 따른 $25{ }^{\circ} \mathrm{C}$ 에서 열 확산도를 나타낸 것이다. 그림에서 알 수 있듯이 카 본블랙의 함량이 증가함에 따라 열 확산도가 0.241 $\mathrm{mm}^{2} / \mathrm{s} \sim 0.420 \mathrm{~mm}^{2} / \mathrm{s}$ 범위에서 증가하는 것을 알 수 있다. 이것은 카본블랙을 함유하고 있는 반도전 수지내 이온성 불순물의 영향이라고 사료된다.

재료들은 열 확산도가 높을수록 외부로의 열 확 산이 빠르기 때문에 밀페된 구조에서는 주위의 온 도를 상승시키는 효과를 초래한다. 즉, 낮은 온도 에서도 쉽게 열 열화가 발생될 수 있다. 이와 같은 결과는 그림 1-4 및 포 3 의 열용량과 용융온도를 통해서 쉽게 알 수 있다. 즉 카본블랙의 함량이 40 $\%$ 인 시편들의 경우, 낮은 열 용량과 용윰온도을 나타내는 반면 열 확산도는 높다. 이것은 높은 열 확산도로 인해 시편들을 용융시키기에 필요한 열 용량이 적게 소모되는 동시에 저온에서 용융이 이 루어질 수 있다는 것을 의미한다 $[7,9]$.

아쉽게도 $\mathrm{A} 1, \mathrm{~A} 2$ 및 $\mathrm{A} 3$ 수지에 대한 열 확산도 를 촉정하지 못하였다. 그러나 ICPAES와 DSC의 실험 결과에 의하면 $\mathrm{A} 1, \mathrm{~A} 2$ 및 $\mathrm{A} 3$ 수지의 열 확 산도는 측정용 수지에 비해 높게 나타날 것으로 사료된다. 이 부분에 대한 결과는 추후 실험을 통 해 제시할 것이다.

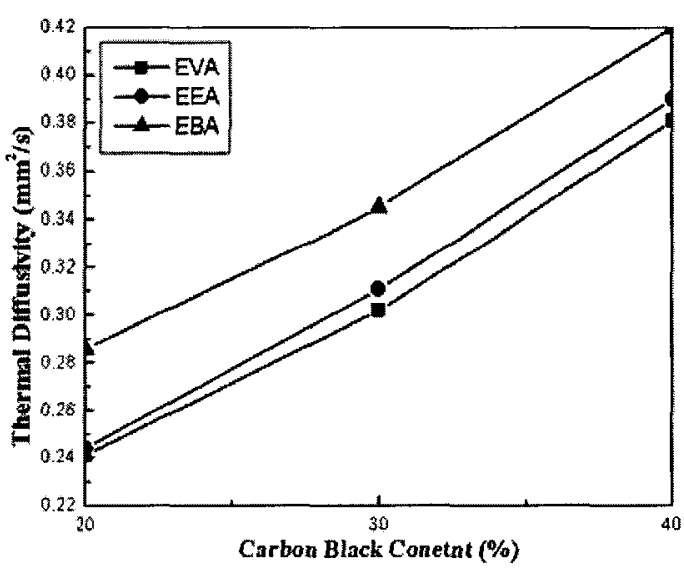

그림 5. 카본블랙의 함량에 따른 시편들의 열 확 산도.

Fig. 5. Thermal diffusivity of semiconductive materials by content of carbon black. 
표

5. 카본블랙의 함량에 따른 시편들의 열 확산도.

Table 5. Thermal diffusivity of specimens by content of carbon black.

\begin{tabular}{|l|c|}
\hline 종류 & Thermal diffusivity $\left[\mathrm{mm}^{2} / \mathrm{s}\right]$ \\
\hline \hline$\# 1$ & 0.241 \\
\hline$\# 2$ & 0.302 \\
\hline$\# 3$ & 0.381 \\
\hline$\# 4$ & 0.244 \\
\hline$\# 5$ & 0.311 \\
\hline$\# 6$ & 0.390 \\
\hline$\# 7$ & 0.286 \\
\hline$\# 8$ & 0.345 \\
\hline$\# 9$ & 0.420 \\
\hline
\end{tabular}

그림 5와 포 4에서 $\mathrm{EBA}$ 의 열 확산도가 가장 높 게 나타나고 있으며 $\mathrm{EVA}$ 와 $\mathrm{EEA}$ 의 열 확산도는 비슷하게 개시하여 카본블랙의 함량이 쯩가한 이 후에는 $\mathrm{EEA}$ 가 다소 높게 나타난 것을 알 수 있다.

그러나 EVA와 $\mathrm{EEA}$ 의 열 확산도 차이는 크지 않음을 알 수 있다. 이와 같은 열 분석 결과를 통 해 대체적으로 $\mathrm{EEA}$ 의 열적 안정성이 다른 시편들 에 비해 우수함을 알 수 있었다.

\section{4. 결 론}

본 논문에서는 전력케이블내 반도전 재료의 신 뢰성을 향상시키기 위해, 반도전 재료내의 카본블 랙이 함유하고 있는 이온성 불순물들에 따른 열적 특성을 알아보았다.

그 결과, 카본블랙의 함량이 증가함에 따라 여 러 시편에서 이온성 불순물들이 다량 검출되었으 뎌, 특히 국내에서 제조되어 사용중인 $\mathrm{A} 1, \mathrm{~A} 2$ 및 $\mathrm{A} 3$ 수지에서 가장 많은 불순물들이 검출되었다.

$\mathrm{DSC}$ 실험 결과, 이온성 불순물들을 다량 함유 하고 있는 카본블랙의 함량이 중가할수록 열용량 과 용융온도가 함께 감소하는 것을 알 수 있었다. 이것은 카본블랙이 함유하고 있는 이온성 불순물 들이 외부에너지에 의해 자극을 받아서 자유운동 에너지가 증가한 결과라고 사료된다.

마지막으로 시편들의 열 확산도를 측정한 결과, 카본블랙의 함량이 증가함에 따라 열 확산도가 증 가하는 것을 알 수 있었다. 이것은 높은 열 확산도
로 인해 시편들을 옹융시키기에 필요한 열 옹량이 적게 소모되는 동시에 저온에서 용윰이 쉅게 이루 어질 수 있다는 것을 의미한다.

이와 같은 결과를 톻해 얻을 수 있는 것은 카본 블랙이 함유하고 있는 이온성 불순물들이 반도전 수지에 지대한 악영향을 미쳐 열화를 초래할 수 있다는 것이다. 따라서 아온성 불순물들을 최소화 하는 방안이 강구되어야 한다.

\section{감사의 글}

본 논문은 전력기술기초연구과제 R-2003-B-33501의 지원에 의하여 수행된 과제임.

\section{참고 문헌}

[1] 한재홍, 김상준, 권오형, 강희태, 서광석, “반도 전층내 불순물이 전력케이블의 신뢰도에 미치 는 영향", 전기학회논문지, 46 권, 1 호, p. 19 , 1997.

[2] E. F. Steennis and F. H. Kreuger, "Water treeing in polyethylene cables", IEEE Trans. DEI, Vol. 25, p. 989, 1990.

[3] M. T. Shaw and S. H. Shaw, "Water treeing in solid dieletrics", IEEE Trans. DEI, Vol. 19, p. $419,1993$.

[4] M. J. Given, "The role of ions in the mechanism of water tree growth", IEEE Trans. DEI, Vol. 22, p. 151, 1987.

[5] 강대용, 오광영, 김용주, 박대희, “절연/반도전/ 절연층에 있어서 유전특성과 절연파괴 현상”, 전기전자재료학회논문지, 11권, 6호, p. 163, 1998.

[6] 한전 표준 구매시방서, " $22.9 \mathrm{kV}$ 동심중성선 전력케이블", $\mathrm{ES} \mathrm{126-650} \mathrm{664.,} 2001$.

[7] 한재홍, 서광석, 김상준, "에틸렌 비닐 아세테이 트 공중합체/에틸렌 아크릴산 공중합체 블렌드 의 이온투과 및 물리적 성질", 전기학회논문지, 45권, 9호, p. 1282, 1996.

[8] 박수진, 조기숙, M. Zaborski, L. Slusarki, “충 전재-탄성체 상호작용. 6. 산소 플라즈마 처리 가 카본볼랙 표면특성에 미치는 영향”, 엘라스 토머, 37권, 2호, p. 99, 2002.

[9] 전용구, 김재경, 함덕순, 김진석, " $\mathrm{EVA}$ 의 Vinyl Acetate 함량변화에 따른 열적-기계적 성질 연 구", 폴리머, 15권, 4호, p. 402, 1991. 